\title{
Effect of Stereotactic Hematoma Aspiration on the NSE Expression after Experimental Intracerebral Hemorrhage*
}

\section{Zhaoxing Li ${ }^{1}$, Yanan Wang ${ }^{2}$, Chengjie Sun ${ }^{3}$, Xiaoying Wang ${ }^{1}$, Kai Luo', Hongyan Zhang ${ }^{1}$, Ning Gu1, Dehui Zhu1}

\author{
${ }^{1}$ Institute of Integrative Medicine, Qingdao University Medical College, Qingdao, China \\ ${ }^{2}$ Department of Emergency Neurology, the Affiliated Hospital of Qiingdao University, Qingdao, China \\ ${ }^{3}$ People's Hospital of Laixi, Qingdao, China \\ *Supported by a grant from Municipal Science and Technology of Qingdao (09-1-1-32-nsh).
}

\begin{abstract}
Objective To observe the effect of stereotactic hematoma aspiration on the expression of neuron-specific enolase (NSE) in perihematomal tissue after intracerebral hemorrhage. Methods The model of intracerebral hemorrhage were established by using inracerebral stereotaxic injection of type IV collagenase method in male adult Wistar rats and were randomly divided into sham operation group, intracerebral hemorrhage group, and hemorrhage aspiration group. The neurological impairment in rats were evaluated by means of Bederson four grade. The morphology of nerve cells in cortex were observed by the hematoxylin-eosin staining. The expression of NSE in cortex was detected respectively by the immunohistochemistry and Western Blot. Results The expression of NSE in the peripheral region of hematoma in hematoma aspiration group and intracerebral hemorrhge group was significantly higher than that in sham operation group each time point after intracerebral hemorrhage $(P<0.05)$. The expression of NSE in the peripheral region of hematoma in hematoma aspiration group was slightly higher than that of intracerebral hemorrhage ground one day after intracerebral hemorrhage $(P<0.05)$, but there was no significantly difference. Compared with intracerebra hemorrhage group, the expression of NSE in the peripheral region of hematoma in hemorrhage aspiration group was significantly decreased on $3^{\text {rd }}$ and $5^{\text {th }}$ day after intracerebral hemorrhage. Compared with hemorrhage aspiration group, the numbers of positive cells were significantly increased and the damage of the neurons in cortex was worsened than that in intracerebra hemorrhage group. Conclusion The expression of NSE in perihematomal tissue after intracerebral hemorrhage was increased obviously after intracerebral hemorrhage. However, early hematoma aspiration could weaken the expression of NSE, reduce the number of neuronal degeneration cells, and improved neurobehavioral function significantly after intracerebral hemorrhage.
\end{abstract}

Keywords: NSE; Intracerebral Hemorrhage; Stereotactic Hematoma Aspiration ; Rat

This article is published under the terms of the Creative Commons Attribution License 4.0 Author(s) retain the copyright of this article. Publication rights with Alkhaer Publications. Published at: http://www.ijsciences.com/pub/issue/2015-08/

DOI: 10.18483/ijSci.795; Online ISSN: 2305-3925; Print ISSN: 2410-4477 


\section{Background}

The intracerebral hemorrhage (ICH) is a common cerebrovascular diseases, accounting for $10 \%$ to $20 \%$ of all strokes, becoming the high morbidity, high mortality and high rates of relapse, and seriously influencing people's daily lives. Neuron-specific enolase (NSE), a major acid protease in neurons and neuroendocrine cells, is a dimeric protein with tissue specificity of the expression of three different subunits $(\alpha, \beta$ and $\gamma)[1]$. As a marker of neuronal damage, it reflects the severity of brain hemorrhage and neurological deficit, and has high sensitivity and specificity[2]. In recent years, the stereotactic hematoma aspiration is a common method for treatment of ICH. The pathological process of secondary injury after ICH can be blocked by early aspiration treatment, so as to achieve therapeutic purposes[3]. This research attempts to establish the model of ICH by using inracerebral stereotaxic injection of type IV collagenase method in male adult Wistar rats, and observes the changes of NSE protein in perihematomal tissue, neuronal morphology, and neuroethology changes after stereotactic hematoma aspiration intervention. This is used to evaluate the effect of stereotactic hematoma aspiration, to provide evidence for clinical effective treatment and scientific evaluation of $\mathrm{ICH}$.

\section{Materials and Methods}

1.1 Experimental animals Total of 135 adult healthy male Wistar rats , SPF grade, weight 220-250g, supplied by the Experiment Animal Center of Qingdao drug inspection Institute (SCXK (lu) 20100010). The disposition on animals in the experiments are in accordance with the relevant provisions of the guidance to take care of the experimental animals issued by the Science and Technology Department of the People's Republic of China (The Ministry of Science and of the People's Republic of China: Guidance Suggestions for the Care and Use of Laboratory Animals; 2006). All animals were acclimatized for a week and allowed free access to food and water in the room temperature
$(22 \pm 2)^{\circ} \mathrm{C}$ and humidity of $50 \%$ to $70 \%$ with natural light and to avoid too much noise and other disturbances and fasting for $12 \mathrm{~h}$ before operation.

\subsection{Experimental methods}

1.2.1 Animal models The model of ICH were established by using inracerebral stereotaxic injection of type IV collagenase method[4]. Firstly, the healthy male Wistar rats were weighed and anesthetized by injecting intraperitoneally $10 \%$ chloral hydrate $(300 \mathrm{ml} / \mathrm{kg})$. Then the rats were placed in a brain stereotactic apparatus (Jiangwan type IC, Shanghai Precision Instrument Factory), keep anterior bregma and posterior bregma basically balance. A hole of diameter $0.8 \mathrm{~mm}$ was drilled by a standard dental drill (coordinates: $0.2 \mathrm{~mm}$ anterior, $5.5 \mathrm{~mm}$ ventral, and $3 \mathrm{~mm}$ lateral to the bregma), through which a $8 \#$ needle was inserted. Then $0.8 \mu \mathrm{l}$ of normal saline containing $0.5 \mathrm{U}$ of collagenase (Type IV, c8160, Sigma) were infused slowly into the brain during 5 minutes[5]. When the injection was finished, the needle remained in place for 10 minutes to prevent back-leakage before being slowly withdrawn. The hole was then sealed with bone wax, the incision was sutured closed, and the animals were returned to the animal house and followed during the recovery period.

\subsection{Intervening measure}

1.3.1 Sham operation group $(n=45)$ : The rats were injected with $0.8 \mu 1$ normal saline after drilling. At $12 \mathrm{~h}, 10 \mathrm{~h}$ after injecting with collagenase, the rats were respectively inserted by a $8 \#$ needle which were stayed for 15 minutes, and without aspirate and treatment.

1.3.2 Intracerebral hemorrhage group $(n=45)$ : The rats were injected with $0.5 \mathrm{U}$ of collagenase in $0.8 \mu \mathrm{l}$ of NS. The rest of operation procedures is the same to the sham operation group.

1.3.3 Hemorrhage aspiration group $(n=45)$ : The rats were firstly injected with collagenase to established ICH model $10 \mathrm{~h}$ before treatment, then injected with 
$3000 \mathrm{U}$ of urokinase in $5 \mu \mathrm{l}$ of NS by a $8 \#$ needle which were stayed for 15 minutes. Two $2 \mathrm{~h}$ after the urokinase injected, a $8 \#$ needle was inserted along the same location and depth and aspirated 3 times repeatedly to observe the amount of bleeding.

\subsection{Collection of spcimens}

1.4.1 Pathological section: After the model of ICH were established scccessfully, on $1^{\text {st }}, 3^{\text {rd }}$ and $5^{\text {th }}$ day, each group was randomly chosen 5 rats to anesthetized by injecting intraperitoneally $10 \%$ chloral hydrate $(300 \mathrm{mg} / \mathrm{kg})$, and perfused with $200 \mathrm{ml}$ of normal saline from heart into the aorta. The brain was completely removed within 90 seconds and fixed in $4 \%$ formaldehyde for $2 \mathrm{~h}$, then soaked in distilled water for $4 \mathrm{~h}$. Dehydrated using a graded ethanol series, hyalinized via dimethylbenzene, embedded in paraffin, and sectioned at a thickness of $5 \mu \mathrm{m}$, posted in slide glasses with poly-L-Lysine, and stored in room temperature.

1.4.2 Extraction of total protein: After the model of ICH were established scccessfully, on $1^{\text {st }}, 3^{\text {rd }}$ and $5^{\text {th }}$ day after $\mathrm{ICH}$, each group had 5 rats to be chosen randomly and were anesthetized by injecting intraperitoneally $10 \%$ chloral hydrate $(300 \mathrm{mg} / \mathrm{kg})$, perfused with $200 \mathrm{ml}$ of normal saline from heart into the aorta, underwent craniotomy to remove the brain completely. Then $100 \mathrm{mg}$ of ICH brain tissue from each rats as above was collected and placed into 1.5 $\mathrm{ml}$ Eppendorf tubes. Then, $1 \mathrm{ml}$ of cell lysis buffer was added at a proportion of $1 \mathrm{mg}: 10 \mu \mathrm{l}(1 \mathrm{ml}+10$ $\mu \mathrm{mol} / \mathrm{L}$ PMSF, No. P0013B, Biyuntian Biotech. Co. Ltd., China). The tissues were ground at $4^{\circ} \mathrm{C}$ in an ice bath, completely lysed with gentle shaking at $4^{\circ} \mathrm{C}$ for $30 \mathrm{~min}$, centrifuged at $10,000 \mathrm{r} / \mathrm{min}$ for $20 \mathrm{~min}$ at $4^{\circ} \mathrm{C}$ (Eppendorf 5801, Germany), and the supernatant was collected into a fresh Eppendorf tube. Protein concentrations was determined using an enhanced BCA protein assay kit (No. P0010, Biyuntian Biotech Ltd., China). Protein samples were mixed with $5 \mathrm{X}$ SDS-PAGE sample loading buffer, followed by denaturation at $100^{\circ} \mathrm{C}$ for $10 \mathrm{~min}$, and stored at $-80^{\circ} \mathrm{C}$.

\subsection{Evaluation Index}

1.5.1 Neurobehavioral function test: After the model of ICH were established scccessfully, referencing to Bederson scoring method: rats were held gently by the tail, raised $10 \mathrm{~cm}$ above desk, normal rats extend both forelimbs straight forward.The rats had no other neurological deficit were assigned grade 0; the rats with any amount of consistent forelimb flexion and no other abnormality were graded 1; the severely dysfunctional rats which had consistently reduced resistance to lateral push toward the paretic side were graded 2; the rats that circled toward the paretic side consistent- ly were graded 3 .

1.5.2 HE staining: Each rat was taken five paraffin sections, after routine de-waxing and washing, the histological sections were stained with hematoxylin for $5 \mathrm{~min}$, the color was separated with $1 \%$ hydrochloric acid alcohol for $20 \mathrm{~s}$, the section were back to blue with $1 \%$ ammonia for $30 \mathrm{~s}$, dyed with eosin for $5 \mathrm{~min}$, dehydrated in increasing concentrations of alcohol, hyalinized with dimethylbenzene, and sealed with neutral gum. Under a microscope (Leica DMI400, Germany), nerve nuclei is blue and the cytoplasm is red. Under a microscope at $400 \mathrm{X}$ magnification, the morphology of the neurons in the cortex around $\mathrm{ICH}$ was observed. The neuron morphology in the cortex around ICH was observed in four non-overlapping visual fields under microscope at 400X magnification and presented as denatured cell index (DCI): the number of denatured cells / total cells in the visual field (Mean \pm SD).

1.5.3 Immunohistochemistry: Rabbit anti-rat NSE monoclonal antibody (1:1000, Ab53025, Abcam); 3,3-diaminobenzidine (DAB) and Power Vision two-step histo-staining reagent (PV-6001, ZSGB-Bio.Co. Ltd., Beijing, China). The paraffin sections were de-waxed and washed according to routine procedures. Then The immunohistochemical procedures were performed in strict accordance with Power Vision two-step histo-staining reagent. The positive cells were enumerated and averaged in five random views of cortex from four serial slices under a microscope at 400X magnification (Leica DMI400, Germany). The positive cell index (PCI $=$ positive cells / total cells) was calculated and used to indicate the NSE expression levels. 
1.5.4 Western blotting: The protein sample removed was fully dissolved from freezer at $-80^{\circ} \mathrm{C}$ treated as above, and were mixed with $5 \mathrm{X}$ SDS-PAGE sample loading buffer in accordance with the ratio of 1:4, followed by denaturation at $100^{\circ} \mathrm{C}$ for $10 \mathrm{~min}$, and stored at $-80^{\circ} \mathrm{C}$ until further analysis. Took protein sample $10 \mu \mathrm{g}$ to subject to electrophoresis on $10 \%$ SDS-polyacrylamide gels (SDS-PAGE) and transferred onto PVDF membrane (Millipore, Bedford, MA, USA) using a wet electrophoretic transfer system, which was blocked for $1.5 \mathrm{~h}$ at room temperature with $5 \%$ nonfat milk in Tris-buffered saline and then probed with primary antibodies: NSE, 1:5000 in Tris-buffered saline/Tween-20 (TBST) buffer at $4^{\circ}$ Covernight with gentle shaking. And the membrane was followed by washing and incubation with a matching secondary antibody (1:5000, BA1054, Boster, China) for $1 \mathrm{~h}$ with gentle agitation at room temperature. Antigens are detected by Immobilon TM Western chemiluminescent HRP substrate (Millipore, USA) and scanned in a Bio-Rad 2000 gel imaging system (Bio-Rad, Hercules, CA, USA). Gray values of the protein bands were analyzed by using Quantity One software (Bio-Rad). Gray value (pixel intensity) was used to quantify protein content, and the value of every sample was normalized against that of $\beta$-actin $(42 \mathrm{kD})$ as an internal control. The relative value of target protein was calculated as follows: gray value of NSE/gray value of $\beta$-actin. The experiment was repeated 5 times and the results are presented as the means tstandard deviation.

\subsection{Statistical analysis.}

Quantitative data were expressed as mean \pm SD. Statistical comparisoisons were conducted using analyses of variance followed by LSD- $t$ test for intergroup comparisons. The Student's $t$-test was used in analysis of paired samples. Differences with $P<0.05$ were considered statistically significant.

\section{Results}

\subsection{Neurobehavioral function score (Fig 1)}

On $2^{\text {nd }}$ day after $\mathrm{ICH}$, the neurobehavioral function scores of rats in $\mathrm{ICH}$ group and hemorrhage aspiration group were significantly higher than those in sham operation group ( $t=30.82, P<0.01)$; on $1^{\text {st }}$ day after $\mathrm{ICH}$, the neurobehavioral function scores of rats in hemorrhage aspiration group were slightly higher than those in ICH group, but no significant difference $(t=0.63, P>0.05)$ existed; on $2^{\text {nd }}, 3^{\text {rd }}$ and $5^{\text {th }}$ day after $\mathrm{ICH}$, the neurobehavioral function scores of rats in hemorrhage aspiration group were significantly lower than those in ICH group $(t=2.357,3.54,2.53, P<0.05)$.

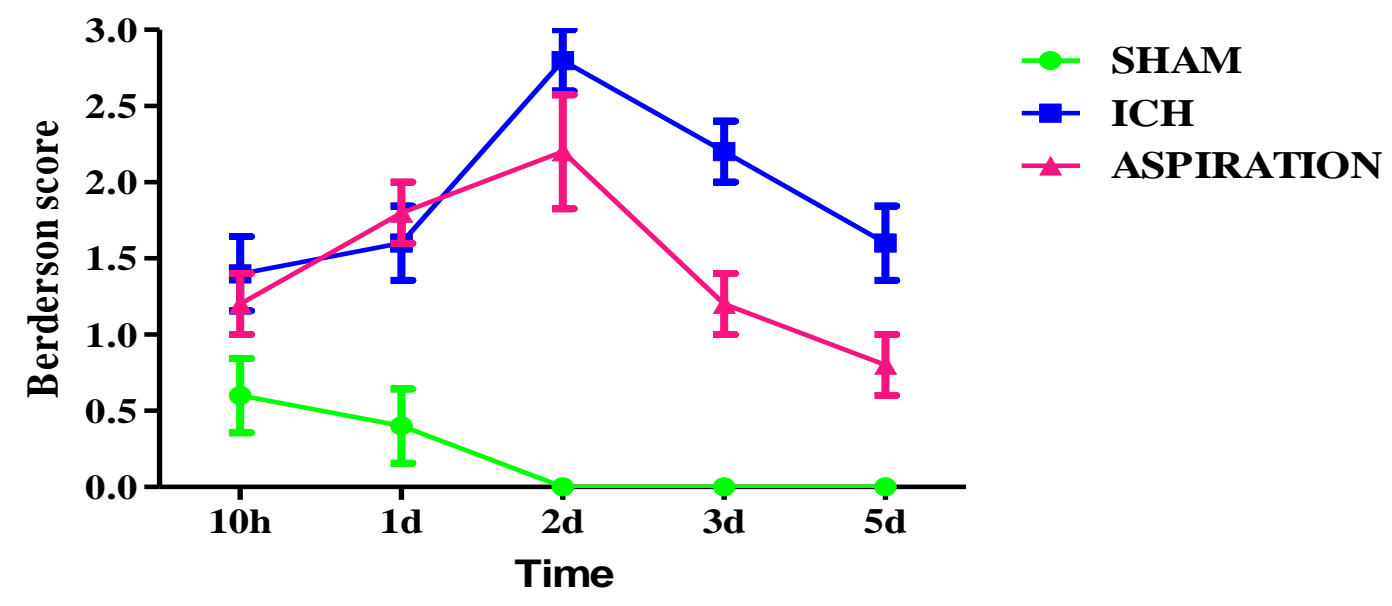

Fig 1 Comparison of behavior score among rats of each group

\subsection{Histopathological changes (Fig 2, Table1)}

HE staining revealed that the nerve cells in the parietal cortex of rats in sham operation group arranged well on $3^{\text {rd }}$ day, with complete structure and even color. Compared with the sham operation group, the nerve cells in the parietal cortex of rats in ICH group and hemorrhage aspiration group on $3^{\text {rd }}$ day after ICH arranged irregularly, the nuclei were condensed and deeply dyed, the section of the nerve cells had become to vacuoles after degeneration and necrosis $(t=12.86,5.44, P<0.05)$. On $3^{\text {rd }}$ day after $\mathrm{ICH}$, the number of denatured cells in hemorrhage aspiration group was significantly decreased than that of ICH group $(t=7.15, P<0.05)$. 


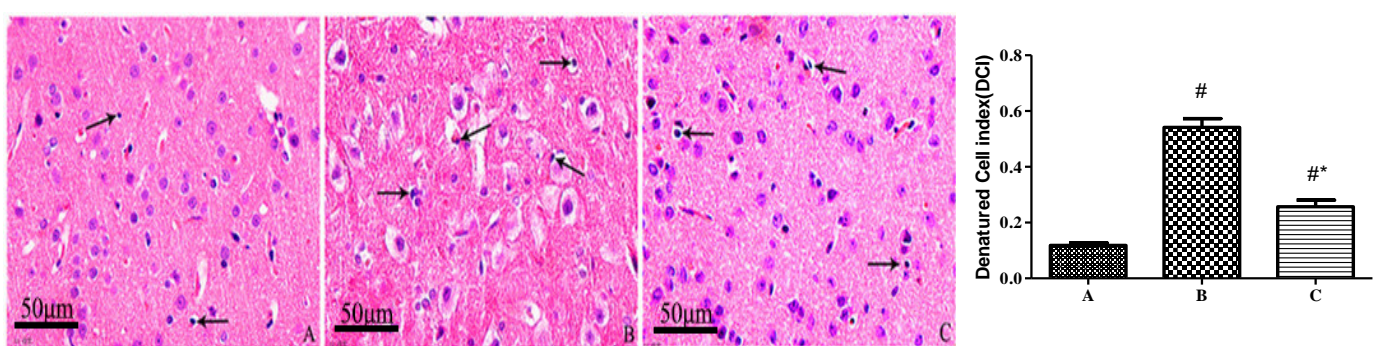

Fig 2. The morphology and structure of nerve cells in cortex in different group on $3^{\text {rd }}$ day after ICH, HE $\times 400$. A. Sham operation group; B. IHC group; C. Hemorrhage aspiration group; (

$\longrightarrow$ ): Denatured cells ${ }^{\#} P<0.05$, compared with Sham operation group; $* P<0.05$.

Table 1 The expression comparisonof the DCI in perihematomal tissue on $3^{\text {rd }}$ day after ICH $\quad(\bar{x} \pm$ S)

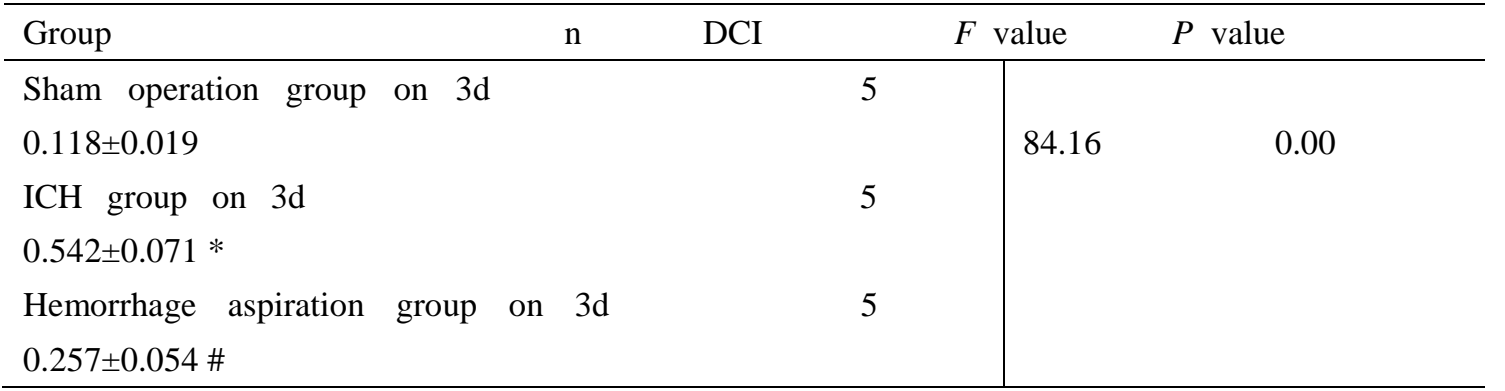

${ }^{*} P<0.05$, compared with Sham operation group; ${ }^{\#} P<0.05$, compared with IHC group.

\subsection{Immunohistochemical analysis (Fig 3,}

\section{Table2)}

The expression of NSE protein in perihematomal tissue after $\mathrm{ICH}$ in each group was different. The expression of NSE protein in sham operation group was weaker and lightly dyed than that of IHC group and hemorrhage aspiration group $(\mathrm{t}=7.52,5.51,14.74$,
$10.85,7.24,4.46, P<0.05)$. On $1^{\text {st }}$ day after ICH, the expression of NSE protein in hemorrhage aspiration group was higher than that of IHC group, but had no indifference $(t=0.48, P>0.05)$. On $3^{\text {rd }}$ and $5^{\text {th }}$ day after $\mathrm{ICH}$, the expression of NSE protein in $\mathrm{ICH}$ group was obviously higher than those of hemorrhage aspiration group $(t=4.08 、 2.54, P<0.01)$.
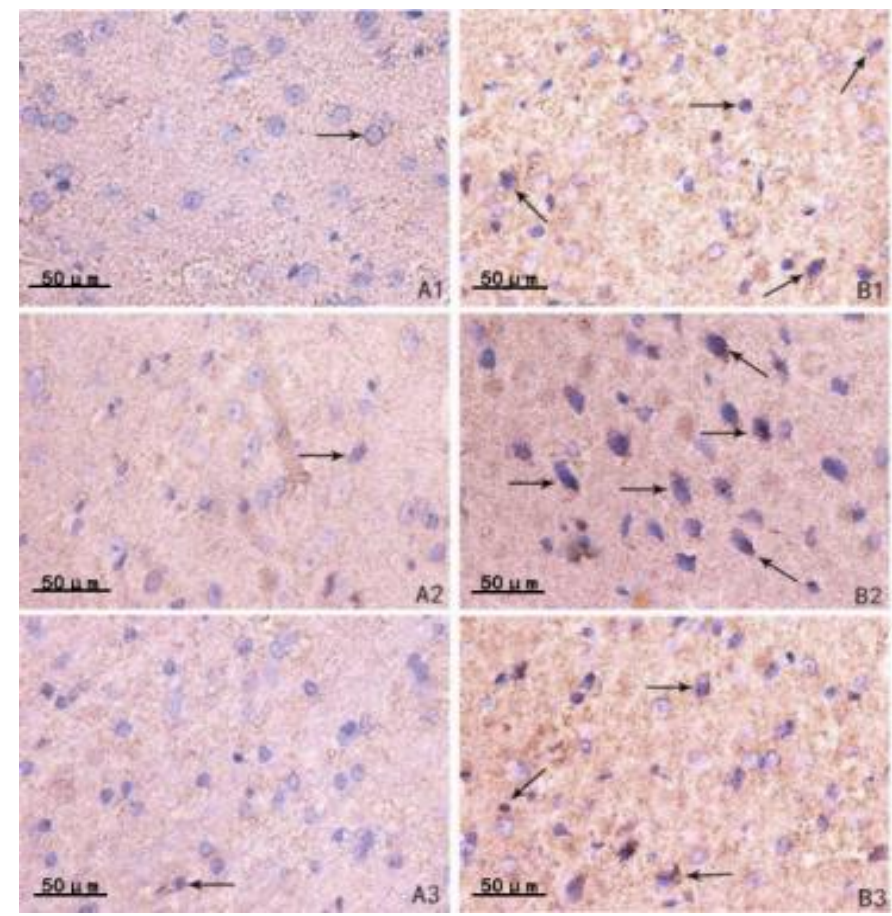

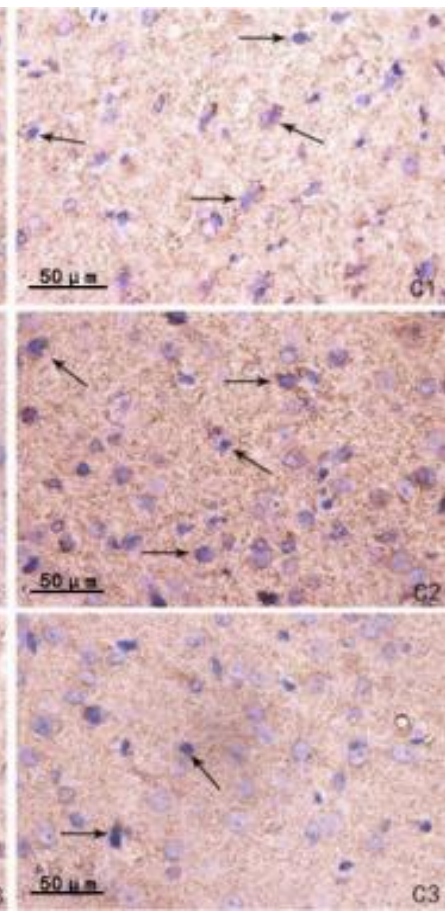




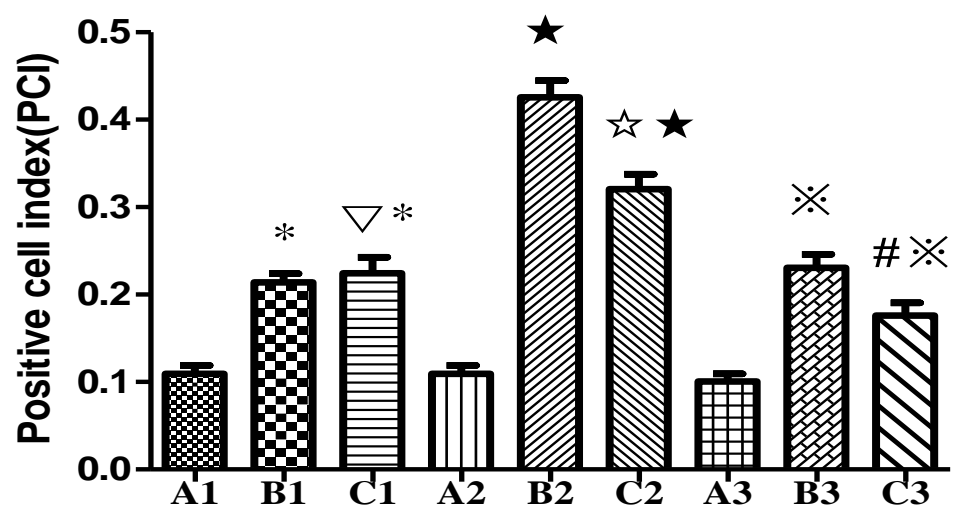

Fig 3 The expression of NSE protein in cortex in each groupof rats, A. Sham operation group; B. IHC group; C. Hemorrhage aspiration group; $(\longrightarrow$ : Positive cells

Note: Fig A were respectively sham operation group 1 d, 3 d, 5 d; Fig B were respectively IHC group 1 d, 3 d, 5 d; fig $\mathrm{C}$ were respectively hemorrhage aspiration group $1 \mathrm{~d}, 3 \mathrm{~d}, 5 \mathrm{~d}$. ${ }^{*} P<0.05$, compared with Sham operation group (A1); ${ }^{\nabla} P>0.05$, compared with IHC group (B1); ${ }^{\star} P<0.05$, compared with Sham operation group (A2); ${ }^{\text {th}} P<0.01$, compared with IHC group(B2); ${ }^{*} P<0.05$, compared with Sham operation group (A3); $P<0.01$, compared with IHC group (B2).

Table 2 The comparisonof the PCI in perihematomal tissue after $\operatorname{ICH}(\bar{x} \pm \mathrm{S})$

\begin{tabular}{|c|c|c|c|c|}
\hline Groups & $\mathrm{n}$ & NSE & $F$ value & $P$ alue \\
\hline A1 & 5 & $0.103 \pm 0.019$ & \multirow{3}{*}{55.64} & \multirow{3}{*}{0.00} \\
\hline B1 & 5 & $0.222 \pm 0.019$ & & \\
\hline $\mathrm{C} 1$ & 5 & $0.232 \pm 0.027 *$ & & \\
\hline A2 & 5 & $0.106 \pm 0.016$ & \multirow{3}{*}{240.51} & \multirow{3}{*}{0.00} \\
\hline B2 & 5 & $0.413 \pm 0.021$ & & \\
\hline $\mathrm{C} 2$ & 5 & $0.319 \pm 0.023 * *$ & & \\
\hline A3 & 5 & $0.099 \pm 0.011$ & \multirow{3}{*}{77.40} & \multirow{3}{*}{0.00} \\
\hline B3 & 5 & $0.239 \pm 0.025$ & & \\
\hline $\mathrm{C} 3$ & 5 & $0.193 \pm 0.015 * * *$ & & \\
\hline
\end{tabular}

$* P>0.05$, compared with IHC group (B1); $* * P<0.05$, compared with IHC group (B2); $* * * P<0.01$, compared with IHC group (B3).

\subsection{Western Bloting (Fig 4, Table3)}

The expression of NSE protein in sham operation group was weaker at each time. On $1^{\text {st }}, 3^{\text {rd }}$ and $5^{\text {th }}$ day after ICH, the expressions of NSE protein in $\mathrm{ICH}$ group was obviously higher than those in sham operation group $(t=6.79,14.47,14.58,13.75,6.24$, $3.44, P<0.01)$; on $1^{\text {st }}$ after $\mathrm{ICH}$, compared with hemorrhage aspiration group, the expression of NSE protein in IHC group sightly lower, but had no indifference $(t=1.79, P>0.05)$; On $3^{\text {rd }}$ and $5^{\text {th }}$ day after $\mathrm{ICH}$, compared with hemorrhage aspiration group, the expression of NSE protein in $\mathrm{ICH}$ group was significantly higher $(t=3.46,2.88, P<0.01)$, while the expression of NSE protein in hemorrhage aspiration group was obviously higher than that in sham operation group $(t=6.24,3.44, P<0.05)$. 

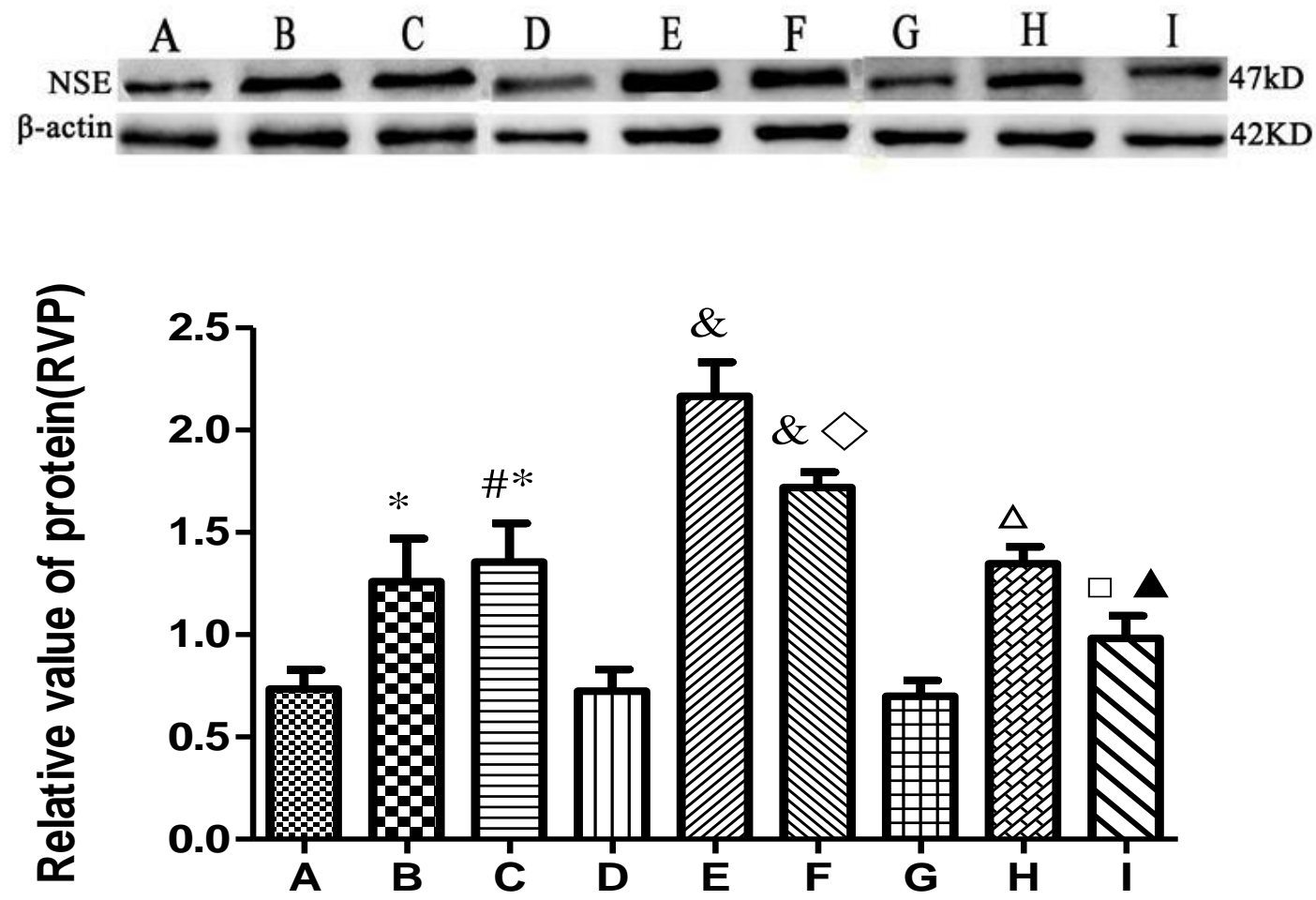

Fig 4The expression of NSE protein was detected by Western blotting. A: sham operation group1d; B: IHC group 1d; C: hemorrhage aspiration group1d; D: sham operation group 3d; E: IHC group 3d; F: hemorrhage aspiration group $3 \mathrm{~d}$; G: sham operation group 5d; H: IHC group 5d; I: hemorrhage aspiration group $5 \mathrm{~d}$. $* P<0.01$, compared with sham operation group $1 \mathrm{~d}$; ${ }^{\#} P<0.05$, compared with IHC group $1 \mathrm{~d}$; ${ }^{\&} P<0.01$, compared with sham operation group $3 \mathrm{~d} ;{ }^{\diamond} P<0.01$, compared with hemorrhage aspiration group $3 \mathrm{~d} ; \Delta P<0.01$, compared with sham operation group $5 \mathrm{~d}$; $\square P<0.05$, compared with sham operation group $5 \mathrm{~d}$; ${ }^{\wedge} P<0.01$, compared with IHC group $5 \mathrm{~d}$.

Table 3 The comparisonof NSE protein expression in perihematomal tissue after ICH $(\bar{x} \pm$ S $)$

\begin{tabular}{|c|c|c|c|c|}
\hline Groups & $\mathrm{n}$ & NSE & $F$ value & $P$ value \\
\hline A & 5 & $0.734 \pm 0.094$ & \multirow{3}{*}{18.90} & \multirow{3}{*}{0.00} \\
\hline B & 5 & $1.259 \pm 0.211$ & & \\
\hline $\mathrm{C}$ & 5 & $1.356 \pm 0.324 *$ & & \\
\hline $\mathrm{D}$ & 5 & $0.724 \pm 0.105$ & \multirow{3}{*}{184.81} & \multirow{3}{*}{0.00} \\
\hline $\mathrm{E}$ & 5 & $2.166 \pm 0.166$ & & \\
\hline $\mathrm{F}$ & 5 & $1.720 \pm 0.634 * *$ & & \\
\hline G & 5 & $0.699 \pm 0.078$ & \multirow{3}{*}{62.70} & \multirow{3}{*}{0.00} \\
\hline $\mathrm{H}$ & 5 & $1.347 \pm 0.083$ & & \\
\hline I & 5 & $0.982 \pm 0.112 * * *$ & & \\
\hline
\end{tabular}

$* P>0.05$, compared with hemorrhage aspiration group1d; $* * P<0.01$, compared with IHC group $3 \mathrm{~d}$; $* * * P<0.01$, compared with IHC group $5 \mathrm{~d}$. 


\section{Discussion}

\subsection{The establishment of stereotactic hematoma aspiration}

To establish the experimental animal model of $\mathrm{ICH}$ is mainly the following 4 kinds of methods: microsphere capsule filling method, autologous blood injection method, the method of spontaneous cerebral hemorrhage, collagenase-induced method[6]. The initial design was injecting the blood of rat tail into right caudate nucleus. But many difficulties were encountered in the process of modeling, such as when the blood was injected slowly, it appears solidification; when the blood was injected fast, it could reflux into the subcutaneous or ventricle; when the blood was injected uniformly, and because the brain tissue density and pressure was big, after the blood was injected $15 \mathrm{~min}$ and slowly pull out of the microinjector, the blood would flow out along the needle hole. After varieties of experiments, the type IV collagenase-induced ICH rat model were chosen. This model is easy and simple, quick and repetition well, and the location and volume of hematoma formation is relatively constant, etc. After making a successful model, this broader clinical application of urokinase to dissolve blood clots was chosen. At $10 \mathrm{~h}$ after the injection of collagenase, rats were anesthetized again, the urokinase was injected. The hematoma was aspirated after observed in 2 hours, aspirated dark red liquid, accompanied by a small amount of blood clots, and the aspiration amount of bleeding was $50-100 \mu$ (equivalent to the human brain hemorrhage of $40-80 \mathrm{ml}$ ).

\subsection{Relationship between NSE and cerebral hemorrhage}

NSE, an intracellular metalloenzyme (phosphopyruvate dehydrogenase), is an important enzyme of the glycolytic pathway. NSE is also a dimeric protein with tissue specificity of the expression of three different subunits $(\alpha, \beta$ and $\gamma)$, and includes five kinds of isozymes $(\alpha \alpha, \beta \beta, \gamma \gamma, \alpha \beta$, $\alpha \gamma)$ [7]. The isozymes $(\alpha \gamma, \gamma \gamma)$ is mainly in neurons and neuroendocrine cells[8]. It has been reported that about 3-8 ng/ml of NSE is present in normal cerebrospinal fluid and serumnd, which increases to thousands of $\mathrm{ng} / \mathrm{ml}$ in cerebrovascular accidents[9]. Some scholars found that among the enolase isozymes, NSE but not non-neuronal enolase (NNE) or muscle-specific enolase (MSE) has neurotrophic activity and that the synthetic peptide corresponding to the C-terminal portion of NSE but not the synthetic peptide of NNE, also promotes the survival of neocortical neurons[10]. Neurotrophic and neuroprotective effects of NSE on cultured neurons from embryonic rat brain. In the case of a lack of oxygen, bleeding or poisoning, the integrity of neuronal cell membrane is damaged, and NSE is not associated with intracellular actin binding, so it is easy to release from the cells, and quickly into the cell gap, through the blood brain barrier to enter the peripheral circulation [11]. Therefore, it can reflect the degree of brain damage by testing the concentration of peripheral blood, and is a highly specific, stable biochemical indicators [12]. Huang et al [13] studies showed that the content of NSE in serum on $1^{\text {st }}$ and $3^{\text {rd }}$ day after ICH was significantly higher than that in the control group. On $5^{\text {th }}$ day after $\mathrm{ICH}$, NSE has begun to decline, but still higher than that in the control $(P<0.001)$, which proved to related to the amount of bleeding. Yang et al[14] reported that the, indicating NSE concentrations and bleeding quantity were positively correlated on $1^{\text {st }}, 3^{\text {rd }}$ and $7^{\text {th }}$ day after ICH $(P<0.01)$, and the NSE level in the small amount of bleeding group was significantly lower than that in the large amount of bleeding group $(P<0.05)$. Lin al.[15] research pointed out that the NSE concentration in blood serum on $6 \mathrm{~h}, 24 \mathrm{~h}, 48 \mathrm{~h}$ after rabbit ICH significantly higher than that in the control group $(P<0.01)$. The NSE concentration in blood serum on $24 \mathrm{~h}$ after rabbit ICH reached the peak, and then have a downward trend. And compared with that on $48 \mathrm{~h}$ after rabbit $\mathrm{ICH}$, the NSE concentration difference on $24 \mathrm{~h}$ after rabbit ICH was statistically significant $(P<0.01)$. Scholars found that the NSE concentration in blood serum of patients with acute brain injury within the first $72 \mathrm{~h}$ was significantly 
higher than the control group, which proved that the NSE concentration in blood serum and the degree of the change of nerve after acute brain injury, and has high predictive value for neural function prognosis[16]. In summary, the NSE concentration in blood serum gradually increased after ICH, 2-3d reached the peak, generally reached a peak in $3-5 d$, and sustained 2-3d. The formation of peripheral edema after $\mathrm{ICH}$, the toxicity of degradation products, and the inflammatory reaction, etc., which led to neuronal cell membrane secondary damage, and which made the NSE further increased. So NSE can be used as a sensitive and reliable marker for ICH[17], and it can also reflect the primary and secondary injury of neurons.

\subsection{The change of NSE protein expression after ICH}

The experimental results show that the hematoma after ICH oppressed surrounding tissue, resulting in neuronal degeneration, necrosis, structural damage, so that a large amount of NSE was released into the blood, resulting in raising NSE in brain tissue and blood. Immunohistochemistry and Western blotting showed that the NSE protein expression on $3 d$ after $\mathrm{ICH}$ rose to the peak, and gradually decreased after several days. On $1^{\text {st }}$ day after $\mathrm{ICH}$, the expression of NSE protein in hemorrhagea spiration group was slightly higher than that of IHC group, and it may be re-anesthetized, injected urokinase dissolve hematoma, and the needle was withdrawn, etc. On $3^{\text {rd }}$ and $5^{\text {th }}$ day after $\mathrm{ICH}$, compared with $\mathrm{ICH}$ group, the expression of NSE protein in hemorrhage aspiration group was significantly lower, and it indicated that the stereotactic hematoma aspiration after ICH is effective to reduce the cerebral edema, which could remove the hematoma, relieve brain damage caused by the pressure of hematoma, and also reduce the inflammatory reaction of the blood breakdown products, etc. So the degeneration and necrosis of neurons was reduced and the NSE expression was decreased. In addition, the experiment confirmed that on the basis of collagenase-induced rat model of $\mathrm{ICH}$, and after using urokinase hematoma, the stereotactic hematoma aspiration had some characteristics that included simple model, good aspiration, good repeatability, light postoperative reaction, low mortality, etc. So it is worth popularizing.

\section{References}

1. Wold F, Ballou CE. Studies on the enzyme enolase. I. Equilibrium studies[J]. J Biol Chem, 1957, 227(1):301-312.

2. Tolan NV, Vidal-Folch N, Algeciras-Schimnich A, et al. Individualized correction of neuron-specific enolase (NSE) measurement in hemolyzed serum samples[J]. Clin Chim Acta, 2013, 424(2013):216-221 http://dx.doi.org/10.1016/j.cca.2013.06.009

3. Bederson JB, Pitts LH, Tsuji M, et al. Rat middle cerebral artery occlusion: evaluation of the model and development of a neurologic examination[J]. Stroke, 1986, 17(3):472-476. http://dx.doi.org/10.1161/01.str.17.3.472

4. Peeling J, Yan HJ, Chen SG, et al. Protective effects of free radical inhibitors in intracerebral hemorrhage in rat[J]. Brain Res, 1998 , 795(1-2):63-70 http://dx.doi.org/10.1016/s0006-8993(98)00253-4

5. Kawai N, Nakamura T, Nagao S. Early hemostatic therapy using recombinant factor VIIa in a collagenase-induced intracerebral hemorrhage model in rats[J]. Acta Neurochir Suppl, 2006, 96:212-217. http://dx.doi.org/10.1007/3-211-30714-1_46

6. Zhang HB, Zhang SM. Rat model of cerebral hemordlage. Foreign Med Sci (Cereb Dis), 2002, 10(6):469-472.

7. $\mathrm{Wu} \mathrm{YC}, \mathrm{Zhao} \mathrm{YB}, \mathrm{Lu} \mathrm{CZ}$, et al. Correlation between serum level of neuron-specific enolase and long-term functional outcome after acute cerebral infarction: prospective study. Hong Kong Med J, 2004, 10(4):251-254.

8. Soh M, Dunlevy J R, Garrett S H, et al. Increased neuron specific enolase expression by urothelial cells exposed to or malignantly transformed by exposure to $\mathrm{Cd}(2)(+)$ or $\operatorname{As}(3)(+)[\mathrm{J}] . \quad$ Toxicol Lett, 2012, 212(1):66-74. http://dx.doi.org/10.1016/j.toxlet.2012.05.003

9. Chiaretti A, Barone G, Riccardi R, et al. NGF, DCX, and NSE upregulation correlates with severity and outcome of head trauma in children. Neurology, 2009, 72(7):609-616. http://dx.doi.org/10.1212/01.wnl.0000342462.51073.06

10. Hattori T, Takei N, Mizuno Y, et al. Neurotrophic and 
neuroprotective effects of neuron-specific enolase on cultured neurons from embryonic rat brain. Neurosci Res, 1995, 21(3):191-198.

http://dx.doi.org/10.1016/0168-0102(94)00849-b

11. Hatfield RH, Mckernan RM. CSF neuron-specific enolase as a quantitative marker of neuronal damage in a rat stroke model.

Brain Res, 1992, 577(2):249-252. http://dx.doi.org/10.1016/0006-8993(92)90280-m

12. Garcia-Alix A, Cabanas F, Pellicer A, et al. Neuron-specific enolase and myelin basic protein: relationship of cerebrospinal fluid concentrations to the neurologic condition of asphyxiated full-term infants. Pediatrics, 1994, 93(2):234-240.

13. Huang GB, Wei SZ, Yao LT, et al. Correlation between serum NSE, Protein S100 $\beta$ and cognitive dysfunction of cerebral hemorrhagic patients. Journal of Brain and Nervous Diseases, 2012, 20(0)251-255.

14. Yang XP, Li QF, Yang RL. Dynamic changes and significance of serum neuron specific enolase during acute period in patients with intracerebral hemorrhage. Chinese
Journal of Practical Nervous Diseases, 2008, 11(09):37-39.

15. Lin J, Wang HO, Lin FC, et al. The significance and change of neuron-specific enolase in acute cerebral hemorrhage of rabbit. Chinese Journal of Practical Nervous Diseases, 2006, 9(01):41-43.

16. Singh HV, Pandey A, Shrivastava AK, et al. Prognostic value of neuron specific enolase and IL-10 in isReferenceschemic stroke and its correlation with degree of neurological deficit. Clin Chim Acta, 2013, 419(2013):136-138. http://dx.doi.org/10.1016/j.cca.2013.02.014

17. Herrmann M, Ebert AD, Galazky I, et al. Neurobehavioral outcome prediction after cardiac surgery: role of neurobiochemical markers of damage to neuronal and glial brain tissue. Stroke, 2000, 31(3):645-650. http://dx.doi.org/10.1161/01.str.31.3.645 